\title{
Effect of loading strain rates on unloading behavior of shot peened materials
}

\author{
Amir Yazdanmehr, Hamid Jahed \\ Fatigue and Stress Analysis Laboratory \\ University of Waterloo \\ Waterloo, Canada \\ amir.yazdanmehr@uwaterloo.ca, hamid.jahed@uwaterloo.ca
}

\begin{abstract}
Shot peening is a process widely used in industry to improve the fatigue life of materials through induced compressive residual stresses that retard crack initiation and growth. In the peening process, there are two stages: 1 ) loading: shot penetrating into target; and 2) unloading: shot rebounding from the target. The strain rates in the loading process are known to be in $10^{5}-10^{6} 1 / \mathrm{s}$ range, having heavy impact on the materials' properties. However, the effect of the loading strain rates on the rebounding stage is not well studied. This paper aims to determine the effects of the loading strain rates on the unloading behavior of a material using FEM method. First, to better understand the material behavior, this study evaluates the loading-unloading responses of one element at high strain rates in different scenarios. Then, it obtains the strain rates during the loading and unloading for the different elements of a material being impinged by one shot. The results show that the unloading behavior of a material depends only on the loading equivalent plastic strain and the strain rate of the unloading step.
\end{abstract}

Keywords: Shot peening, high strain rate, loading-unloading

\section{INTRODUCTION}

Shot peening is the process of impinging small spherical shots on the surface of a target material. These impacts create plastic deformation that leads to the development of compressive residual stress over the few-hundred micrometers layer of a material within the vicinity of the shot. As fatigue cracks are generally initiated from the surface of a material, this compressive stress delay crack initiation and retards crack growth, resulting in improved fatigue life of the material. Rateindependent analytical/numerical methods for calculation of residual stresses [1], with applications in many different engineering fields [2]-[4], and for multiple applications of the process [5] have been established. However, strain rate effects in shot peening cannot be ignored.

Analytical and finite element (FE) modeling has been employed to estimate residual stresses and/or model the process of shot peening. The analytical method was developed based on quasi-static response of a target material to single impingement [6], [7]. It was further developed to consider dynamic effects [8],
[9]. The FE evaluation of residual stress distribution has been established in 2D [10] and 3D modeling [11], [12].

A major issue in modeling is the incorporation of strain rate effect. The strain rates in the shot peening process can be as high as $10^{5}-10^{6} 1 / \mathrm{s}$ [13][11]. Several studies have shown the effect of strain rates in modeling residual stress distribution [11], [13]. Kim et al. [12] showed that the magnitude of the compressive residual stress increases when considering strain rate effect. Meguid et al. [11] showed that strain rate has a significant role in the modeling of residual stress profiles in the peening of AISI 4340. Attempts have also been made to extend quasi-static based analytical solutions [7] to strain rate-dependent solutions [13]. However, a comprehensive review of the literature reveals that there is no study on the effect of loading strain rates on the unloading behavior of a material and its effect on modeling the shot peening process. This paper discusses different loadingunloading scenarios to provide a simple evaluation of material response at different loading and unloading strain rates. The impact of one shot is modeled to capture the strain rate history of the different elements through the depth of a material. Also, necessary modifications for modeling the residual stress distribution have been identified.

\section{MATERIALS AND METHODS}

This paper includes two parts. In part A, the effect of loading strain rates on the unloading behavior of a material is discussed. For better understanding of this effect in general, a virtual material property with an exaggerated strain rate effect has been considered using a one-element FE model. In part B, the actual one shot impact on a steel alloy has been modeled to illustrate the application of findings of the part $\mathrm{A}$ in the shot peening process.

\section{A. Effect of loading strain rate on unloading behavior of materials, using one-element simulation}

To figure out the effect of loading strain rates on the unloading behavior of a material, this section discusses oneelement simulation of a virtual material with an exaggerated dependency on strain rates. The one-element modeling is performed because the loading and unloading conditions can be simply applied and the response of the material can be obtained. The virtual flow curves of the material assigned to the single 
element modeling is shown in Figure 1 for strain rates of 0.1 and $51 / \mathrm{s}$.

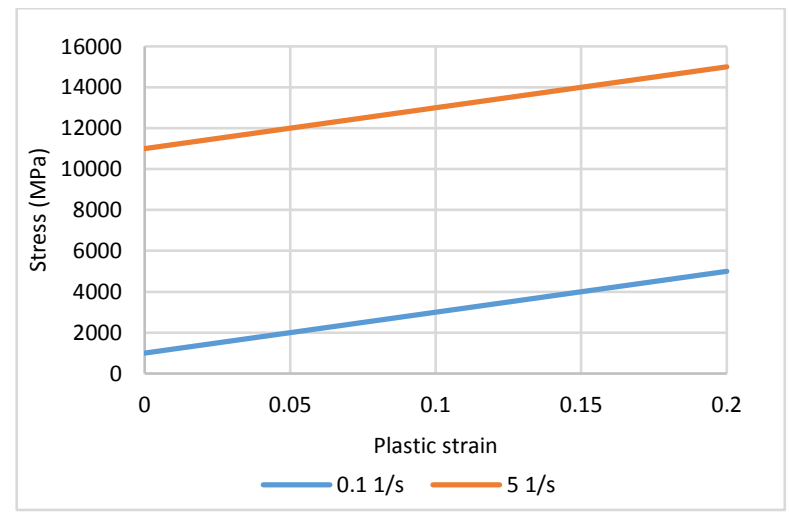

Figure 1. Virtual flow curves of the material used in one-element simulation

The FE analysis is performed using Abaqus software. One element with symmetric boundary condition at $\mathrm{xz}$ plane for its bottom side has been used. In this case, the strain and stress in the $y$-axis are the equivalent strain and stress of the element, respectively. The element size is $1 \times 1 \times 1 \mathrm{~m}$. Figure 2 shows the geometry of one element modeling as well as the boundary, and loading conditions.

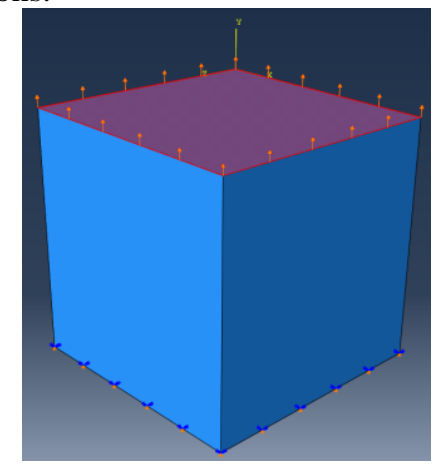

Figure 2. One element modeling geometry

To study the effect of loading and unloading strain rates on the stress-strain response of the material, a simulation using five different strain rate scenarios is considered. Table 1 and Figure 3 describes these different scenarios and represents the strain histories, respectively.

TABLE 1. FIVE LOADING AND UNLOADING SCENARIOS

\begin{tabular}{|c|l|}
\hline Scenario & Description \\
\hline 0 & Quasi-static loading and unloading \\
\hline 1 & Load fast and keep the strain constant \\
\hline 2 & Load fast and then continue loading slowly \\
\hline 3 & $\begin{array}{l}\text { High strain rate loading followed by quasi } \\
\text { static unloading }\end{array}$ \\
\hline 4 & $\begin{array}{l}\text { High strain rate loading followed by } \\
\text { unloading with the same rates as loading }\end{array}$ \\
\hline 5 & $\begin{array}{l}\text { High strain rate loading followed by } \\
\text { unloading with high rates different from } \\
\text { loading rate }\end{array}$ \\
\hline
\end{tabular}

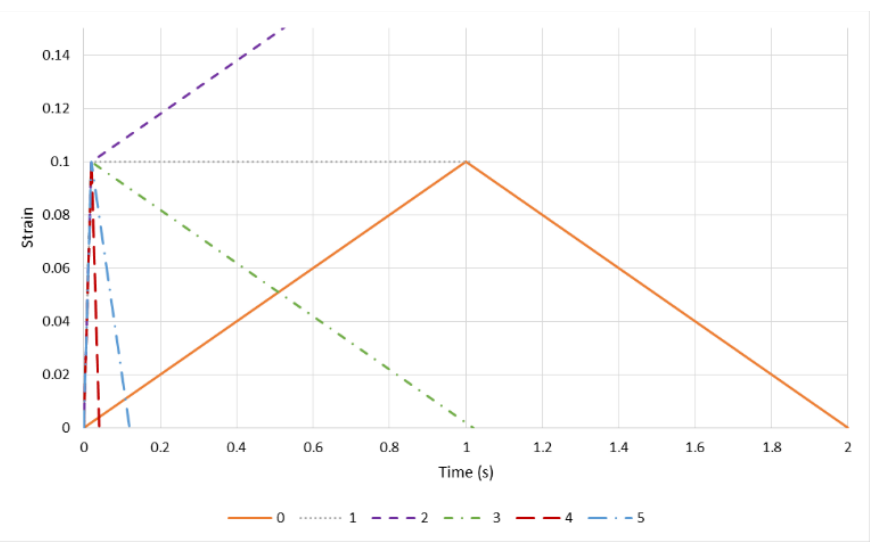

Figure 3. Strain history for the different scenarios shown in Table 1

\section{B. Application on modeling the shot peening process}

As noted, shot peening is a process whereby loading strain rates are high and unloading behavior can be affected by these high loading rates. To determine these effects, this section discusses the finite element modeling of one shot impingement. Abaqus/Explicit was used for modeling the shot peening process. SAE1070 spring steel with dimensions of $76 \mathrm{~mm} \times 19$ $\mathrm{mm} \times 1.29 \mathrm{~mm}$ has been used as the peened material. The stressstrain curve is assumed to be bilinear. Figure 4 presents the stress-strain curve of the SAE 1070 spring steel [14], known as Almen strip type A. The Young's modulus and Poisson's ratio are $200 \mathrm{GPa}$ and 0.31 , respectively. The strain rate effect on the stress-strain curve of this material has been modeled using the Johnston-Cook model with $\mathrm{C}=0.0134$ and a reference strain rate of $75001 / \mathrm{s}$ [13][15].

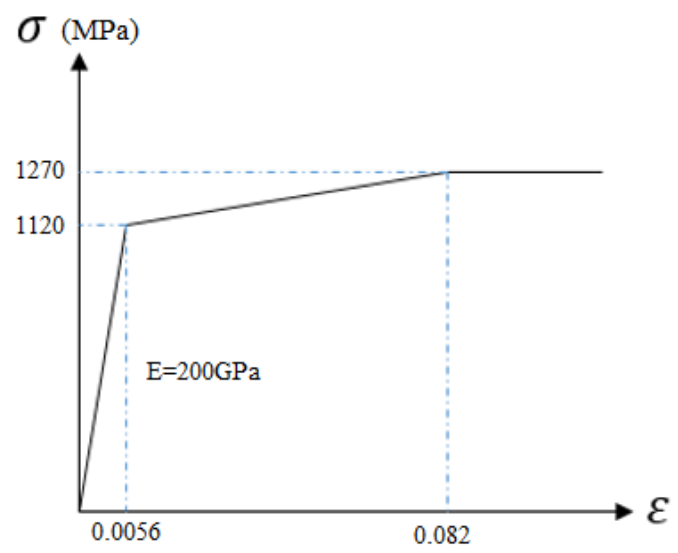

Figure 4. Stress-strain curve of SAE1070 spring steel

Figure 5 shows the flow curves of the material at different strain rates [13]. Table 2 shows the shot properties in the modeling. The shot velocity of $45 \mathrm{~m} / \mathrm{s}$ has been used in this modeling. The steel shot is assumed to be elastic. The target width and height of $5 R$ and $6 R$ are used as suggested in [11], [16]-[18], respectively, where R is the radius of the shot. Eightnode linear brick elements with reduced integration (C3D8R) and a variable element size with minimum size of $5 \times 5 \times 5 \mu \mathrm{m}$ at the impact point are employed for the modeling. 


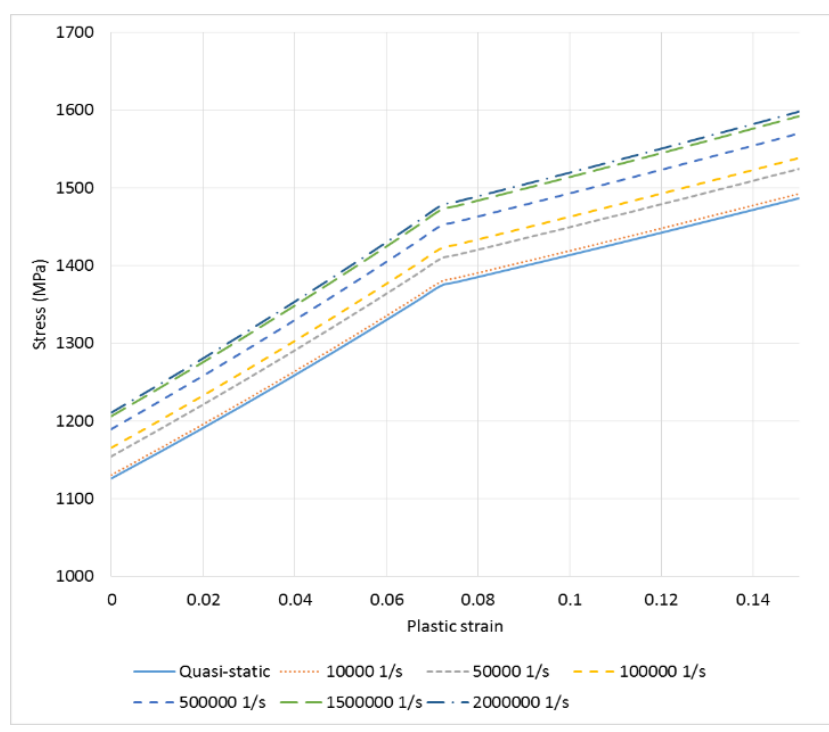

Figure 5. Effect of strain rates on the flow curve of SAE 1070 spring steel [13]

\begin{tabular}{|c|c|c|c|c|}
\multicolumn{7}{c}{ TABLE 2. SHOT PROPERTIES } \\
\hline $\begin{array}{c}\text { Shot } \\
\text { material }\end{array}$ & $\begin{array}{c}\mathrm{E} \\
(\mathrm{GPa})\end{array}$ & $v$ & $\begin{array}{c}\text { Density }(\mathrm{Kg} . \mathrm{m}- \\
3)\end{array}$ & $\begin{array}{c}\mathrm{D} \\
(\mathrm{mm})\end{array}$ \\
\hline Steel shot & 210 & 0.31 & 7800 & 0.4 \\
\hline
\end{tabular}

All degrees of freedom at the bottom side of the target are fixed, and symmetry conditions are applied at the $x z$ and $y z$ planes. The damping model of [11] is used to remove unnecessary oscillations. The penalty contact algorithm with an isotropic coulomb friction coefficient of 0.2 is used [19][20]. Figure 6 shows the single shot geometry and meshed model.

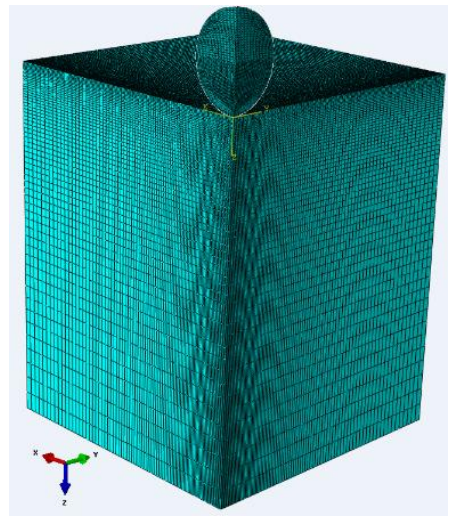

Figure 6. Single shot geometry and meshing

\section{RESULTS AND DISCUSSION}

In this section, the results of one-element and one-shot impingement are discussed.

\section{A. Effect of loading strain rate on unloading behavior of materials, using one-element simulation}

The stress-strain response of one-element model in the loading and unloading with the properties mentioned in Figure 4 are shown in Figure 7. For scenario 0, which is quasi-static loading and unloading, the material follows the given flow curve at the lowest strain rate. In scenario 1 , in which the material is loaded fast and then the loading surface is fixed, the material follows the high strain rate behavior in the loading step, and at the end of the loading, the stress drops to the equivalent stress in the quasi-static stress-strain curve. The equivalent stress at each moment is shown to be a function of equivalent strain and the strain rate at that moment. Scenario 2, in which the material is loaded fast and then the application of tensile strain continues at a low strain rate, reveals that the material follows the stressstrain curve at the high strain rate, then the stress is dropped to follow the rest of the quasi-static loading behavior. In scenario 3 , in which fast loading and then slow unloading happens, the loading behavior of the material is the same as the stress-strain behavior at the high strain rate, but the unloading curve fits the unloading curve of the quasi-static condition. Thus, if the unloading is quasi-static, its stress-strain curve, independent from the loading strain rate, follows the quasi-static unloading curve (scenario 0). Scenario 4 discusses the situation in which both the loading and unloading happen at the high strain rate. In this state, as the strain rates of both the loading and unloading steps are the same, reverse yield happens at the reverse value of the maximum loading stress if the material has isotropic hardening behavior. Finally, scenario 5, in which the loading and unloading strain rates are high but different, shows that the unloading behavior is the same as the response of a material when the unloading strain rate is applied for both loading and unloading steps.

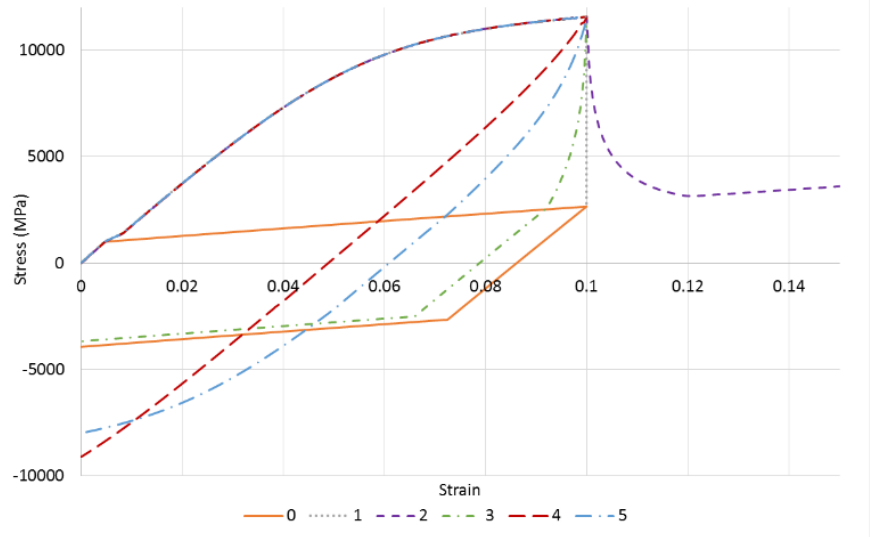

Figure 7. Stress-strain response of one-element in different loadingunloading scenarios

\section{B. Application on modeling the shot peening process}

This part examines the loading and unloading strain rates in the shot peening process, as well as the considerations necessary in modeling of this process, which requires evaluation of the loading-unloading and equivalent stress histories. The strain rates' histories in one-shot impingement for different elements through the thickness are shown in Figure 8. This figure shows that the history of the strain rate is a combination of the different scenarios discussed in the previous section. It also confirms that the unloading strain rates are much lower than the loading ones. The end of the loading step is defined as the moment when the shot is at its maximum penetration depth through the target; after that the shot will rebound. First, as shown, the maximum strain rate happens when a load is applied to an element. After that, the 
strain rates are still high and vanish as the modeling time increases. The time of the unloading is specified in Figure 8. Although the strain rates in the unloading steps are much lower than those in the loading step, their values are still considerable.

Figure 9 shows the variation of equivalent stress for various elements through the depth of the material during the simulation time. The equivalent stresses suddenly increase, at high rates initially, and then continue to increase gradually when the shot is still pressing the target. At the end of the loading step, equivalent stresses drop elastically, with lower strain rates than during the loading step.

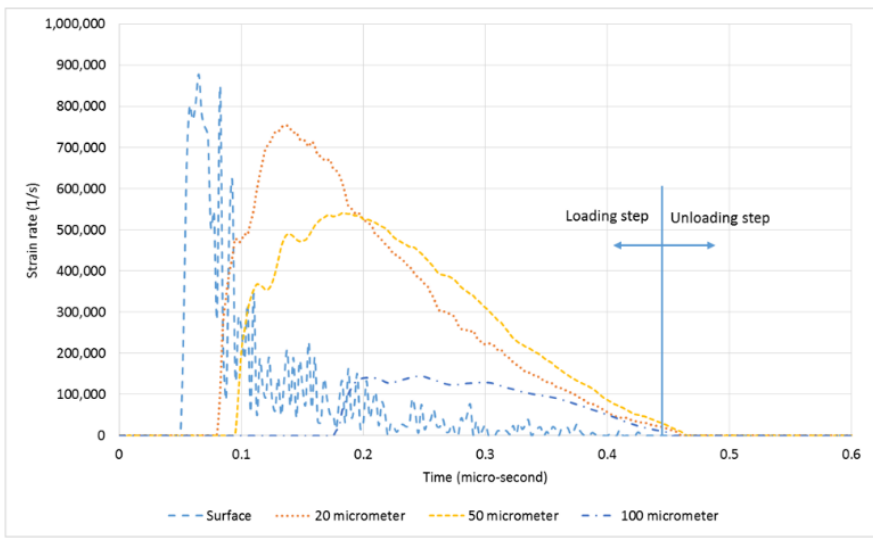

Figure 8. Strain rates of different elements through the thickness elements vs the time of modeling

Figure 10 shows the maximum unloading strain rates of the different elements through the depth of the material. For this peening example, the maximum strain rate in the unloading step occurs for the element that is 50 micrometers below the surface. Although the level of strain rates is one order of magnitude lower than those in the loading step, the strain rate values are in the order of $10^{5} 1 / \mathrm{s}$. Unloading strain rates vanish quickly because when the unloading is ended, the element's strains will stabilized. Thus, the material will follow scenario 3 of the oneelement simulations, in which the unloading curves are fitted to the unloading stress-strain curve of the quasi-static loadingunloading.

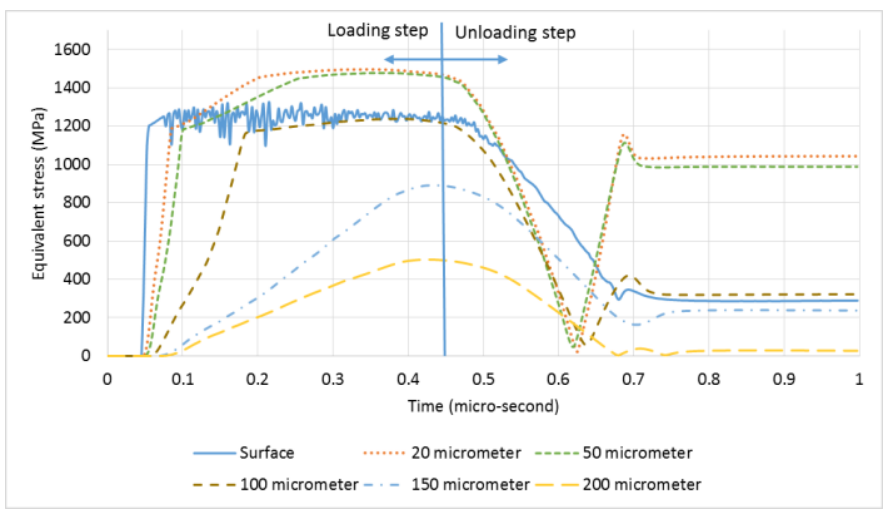

Figure 9. Equivalent stress histories of different elements through the depth of the material during the modeling time

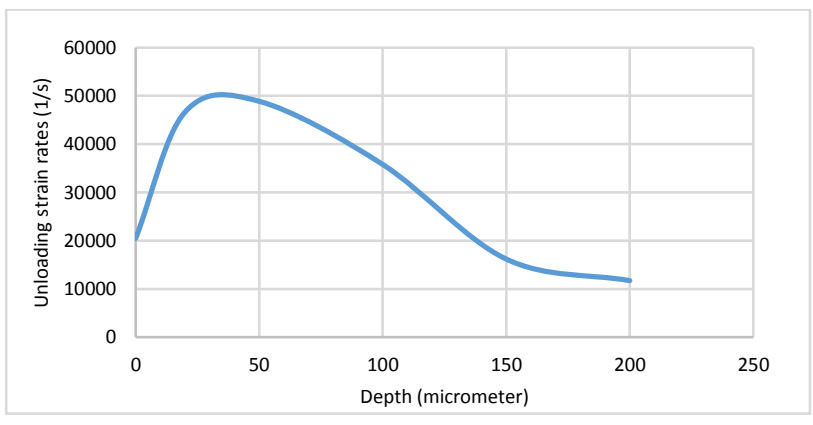

Figure 10. Elastic unloading strain rates of different elements through the depth of the material

\section{CONCLUSION}

The effect of loading strain rates on the unloading behavior of materials has been discussed. The equivalent stress at each moment has been shown to be a function of the equivalent plastic strain and the strain rate of that moment. Also, unloading behavior was found to depend only on the loading equivalent plastic strain and the strain rate in the unloading step, meaning the unloading behavior is independent of the loading strain rate. The fact of considering just the loading strain rates, and scaling the unloading curves based on the loading rates, can lead to an error in modeling the residual stress distribution.

\section{REFERENCES}

H. Jahed and R. N. Dubey, "An Axisymmetric Method of Elastic-Plastic Analysis Capable of Predicting Residual Stress Field," J. Press. Vessel Technol., vol. 119, no. 3, p. 264, 1997.

[2] H. Jahed, S. B. Lambert, and R. N. Dubey, "Variable material property method in the analysis of coldworked fastener holes," J. Strain Anal. Eng. Des., vol. 35, no. 2, pp. 137-142, Feb. 2000.

[3] H. Jahed and S. Sherkatti, "Thermoplastic analysis of inhomogeneous rotating disk with variable thickness," in EMAS Conference of Fatigue, 2000.

[4] E. Kalatehmollaei, H. Mahmoudi-Asl, and H. Jahed, "An asymmetric elastic-plastic analysis of the loadcontrolled rotating bending test and its application in the fatigue life estimation of wrought magnesium AZ31B," Int. J. Fatigue, vol. 64, pp. 33-41, 2014.

[5] H. Jahed, B. A. Moghadam, and M. Shambooli, "ReAutofrettage," J. Press. Vessel Technol., vol. 128, no. 2, p. 223, 2006.

[6] Al-Hassani, "Mechanical aspect of residual stress development in shot peening," 1st International Conference on Shot Peening. pp. 583-602, 1981.

J. K. Li, Y. Mei, W. Duo, and W. Renzhi, "Mechanical approach to the residual stress field induced by shot peening," Mater. Sci. Eng., vol. 147, pp. 167-173, 1991.

[8] A. S. Franchim, V. S. de Campos, D. N. Travessa, and C. de M. Neto, "Analytical modelling for residual stresses produced by shot peening," Mater. Des., vol. 30, no. 5, pp. 1556-1560, 2009. 
[9] H. Y. Miao, S. Larose, C. Perron, and M. Levesque, "An analytical approach to relate shot peening parameters to Almen intensity," Surf. Coatings Technol., vol. 205, no. 7, pp. 2055-2066, 2010.

[10] K. ichiro Mori, K. Osakada, and N. Matsuoka, "Finite element analysis of peening process with plasticity deforming shot," J. Mater. Process. Tech., vol. 45, no. 1-4, pp. 607-612, 1994.

[11] S. A. Meguid, G. Shagal, and J. C. Stranart, “3D FE analysis of peening of strain-rate sensitive materials using multiple impingement model," Int. J. Impact Eng., vol. 27, no. 2, pp. 119-134, 2002.

[12] T. Kim, H. Lee, H. C. Hyun, and S. Jung, "Effects of Rayleigh damping, friction and rate-dependency on 3D residual stress simulation of angled shot peening," Mater. Des., vol. 46, pp. 26-37, 2013.

[13] B. Bhuvaraghan, S. M. Srinivasan, B. Maffeo, and O. Prakash, "Analytical solution for single and multiple impacts with strain-rate effects for shot peening," $C$. Comput. Model. Eng. Sci., vol. 57, no. 2, pp. 137-158, 2010.

[14] J. . Almen and P. . Black, Residual stresses and fatigue in metals. New york: McGrow Hill, 1963.

[15] T. Özel and Y. Karpat, "Identification of constitutive material model parameters for high-strain rate metal cutting conditions using evolutionary computational algorithms," Mater. Manuf. Process., vol. 22, no. 5, pp. 659-667, 2007.
[16] A. Gariépy, S. Larose, C. Perron, and M. Lévesque, "Erratum: Shot peening and peen forming finite element modelling - Towards a quantitative method," Int. J. Solids Struct., vol. 83, p. 183, 2016.

[17] A. Ghasemi, S. M. Hassani-Gangaraj, A. H. Mahmoudi, G. H. Farrahi, and M. Guagliano, "Shot peening coverage effect on residual stress profile by FE random impact analysis," Surf. Eng., vol. 32, no. 11, pp. 861870, 2016.

[18] K. Murugaratnam, S. Utili, and N. Petrinic, "A combined DEM-FEM numerical method for Shot Peening parameter optimisation," Adv. Eng. Softw., vol. 79, pp. 13-26, 2015.

[19] M. Jebahi, A. Gakwaya, J. Levesque, O. Mechri, and K. $\mathrm{Ba}$, "Robust methodology to simulate real shot peening process using discrete-continuum coupling method," Int. J. Mech. Sci., vol. 107, pp. 21-33, 2016.

[20] H. Y. Miao, S. Larose, C. Perron, and M. Levesque, "On the potential applications of a 3D random finite element model for the simulation of shot peening," $A d v$. Eng. Softw., vol. 40, no. 10, pp. 1023-1038, 2009. 